\title{
Does maintenance azithromycin reduce asthma exacerbations? An individual participant data meta-analysis
}

\author{
Sarah A. Hiles $\mathbb{1 0}^{1,2}$, Vanessa M. McDonald ${ }^{1,2,3}$, Michelle Guilhermino ${ }^{2,4}$, \\ Guy G. Brusselle ${ }^{5,6}$ and Peter G. Gibson (1) ${ }^{1,3}$
}

Affiliations: ${ }^{1}$ Centre of Excellence in Severe Asthma and Priority Research Centre for Healthy Lungs, University of Newcastle, Callaghan, Australia. ${ }^{2}$ School of Nursing and Midwifery, Faculty of Health, University of Newcastle, Callaghan, Australia. ${ }^{3}$ Dept of Respiratory and Sleep Medicine, John Hunter Hospital, New Lambton Heights, Australia. ${ }^{4}$ Intensive Care Unit, John Hunter Hospital, New Lambton Heights, Australia. ${ }^{5}$ Dept of Respiratory Medicine, Ghent University Hospital, Ghent, Belgium. ${ }^{6}$ Depts of Epidemiology and Respiratory Medicine, Erasmus Medical Center Rotterdam, Rotterdam, The Netherlands.

Correspondence: Sarah A. Hiles, Centre of Excellence in Severe Asthma and Priority Research Centre for Healthy Lungs, University of Newcastle, University Drive, Callaghan, NSW 2308, Australia.

E-mail: sarah.hilesanewcastle.edu.au

@ERSpublications

Maintenance use of azithromycin in conjunction with existing maintenance asthma treatment reduces exacerbations in severe asthma, eosinophilic asthma and noneosinophilic asthma http://bit.ly/2m $8 \mathrm{mnIx}$

Cite this article as: Hiles SA, McDonald VM, Guilhermino $\mathrm{M}$, et al. Does maintenance azithromycin reduce asthma exacerbations? An individual participant data meta-analysis. Eur Respir J 2019; 54: 1901381 [https://doi.org/10.1183/13993003.01381-2019].

\section{ABSTRACT}

Background: Preventing exacerbations is an important goal of asthma treatment. Long-term treatment with azithromycin may help achieve this. Our aim was to conduct a systematic review and individual participant data (IPD) meta-analysis to examine the efficacy of azithromycin in reducing exacerbations in asthma, and in the subphenotypes of noneosinophilic asthma, eosinophilic asthma and severe asthma.

Method: We completed a systematic search of Embase, MEDLINE, PubMed, Cochrane Library, ClinicalTrials.gov and reference lists of previous systematic reviews in February 2019. We included parallelgroup, double-blind, randomised controlled trials in adults comparing at least 8 weeks of azithromycin treatment with placebo, where the outcome of exacerbations was assessed over at least 6 months. Data were extracted from published sources, Cochrane Risk of Bias Tool was applied and IPD were sought from authors. Reviews were undertaken in duplicate. We conducted an IPD meta-analysis on the primary outcome of exacerbations and a random effects meta-analysis for secondary outcomes.

Results: Three studies were identified $(n=604)$. In the IPD meta-analysis, treatment with azithromycin was associated with a reduced rate of exacerbations (oral corticosteroid course due to worsening asthma, antibiotic use for lower respiratory tract infection, hospitalisation and/or emergency department visits) in asthma as well as in the noneosinophilic, eosinophilic and severe asthma subgroups. Examining each exacerbation type separately, patients with eosinophilic asthma reported fewer oral corticosteroid courses, and patients with noneosinophilic and severe asthma reported fewer antibiotic courses. Azithromycin was well tolerated.

Discussion: Maintenance use of azithromycin reduces exacerbations in patients with eosinophilic, noneosinophilic and severe asthma.

This article has supplementary material available from erj.ersjournals.com

This study is registered at PROSPERO with identifier number CRD42018075259.

Received: 12 July 2019 | Accepted after revision: 31 Aug 2019

Copyright @ERS 2019 


\section{Introduction}

Asthma is a chronic inflammatory airway disease, usually treated with inhaled corticosteroids (ICSs) and long-acting bronchodilators (LABAs). Despite maintenance treatment, many patients experience ongoing illness burden. In particular, among patients with severe or uncontrolled asthma, exacerbations are frequent and impair health outcomes [1]. A 2018 The Lancet Commission called for zero tolerance of asthma attacks [2]. New treatments are needed to accomplish this goal.

Macrolides are a family of antibiotics with anti-inflammatory activity that may benefit patients with asthma [3]. Meta-analytic evidence from studies over short observation periods indicates that the benefit of macrolides is limited [4]; however, recent evidence for the macrolide azithromycin suggests its core benefit may be in the prevention of exacerbations over time [5]. To detect such effects on exacerbation rates, an appropriate observation period of at least 6 months is required.

The 2019 Global Initiative for Asthma guidelines for difficult-to-treat and severe asthma recommend the use of macrolides as an add-on therapy in this population, despite no published data upon which to base this recommendation [6]. For instance, the AMAZES randomised controlled trial (RCT) reported on the effect of azithromycin on exacerbation in an "uncontrolled asthma population" with severe asthma patients included, not severe asthma per se [5]. The AZISAST RCT was in severe asthma, but was underpowered and did not meet its primary end-point of a decreased exacerbation rate [7]. Furthermore, although macrolide antibiotics have been identified as a possible treatment to target noneosinophilic asthma $[7,8]$, beneficial effects of azithromycin have also been reported in adults with eosinophilic asthma [5]. Individual participant data (IPD) meta-analysis can increase power to allow us to address questions regarding subtypes of asthma using existing data from RCTs and reconcile perceived differences between published RCTs.

The aim of this systematic review and IPD meta-analysis was to examine whether maintenance use of azithromycin reduces exacerbations in patients with eosinophilic, noneosinophilic and severe asthma. We hypothesised reduced exacerbations in all groups.

\section{Method}

\section{Protocol registration}

The review protocol was registered with PROSPERO with identifier number CRD42018075259. The original protocol research question sought studies on any macrolides; however, the search only revealed studies on azithromycin, so the research question was revised.

\section{Inclusion and exclusion criteria}

We included published English language studies where adults ( $\geqslant 18$ years old) with diagnosed asthma were randomised to receive a macrolide antibiotic or placebo for at least 8 weeks in a parallel-group, double-blind, placebo-controlled randomised trial and data on exacerbations were reported during at least 6 months of follow-up after starting treatment. Exacerbations could be recorded as number or percentage of patients experiencing an exacerbation, rate of exacerbation or time to first exacerbation; overall and by exacerbation type (i.e. oral corticosteroid (OCS) course due to worsening asthma, antibiotic course for lower respiratory tract infection, hospital admission or emergency department visits due to asthma exacerbations).

While inclusion criteria specified publication in English, non-English publications were retained for abstract review and possible inclusions were noted. As a check, a physician-scientist and native speaker reviewed the titles and abstracts of studies in Chinese; none met the inclusion criteria. Previous reviews indicate that excluding non-English language articles does not lead to systematic bias, although precision of pooled estimates is lowered, as expected from including fewer data points in a meta-analysis [9].

\section{Information sources and search}

Electronic databases (PubMed, Embase, MEDLINE, Cochrane Library (CENTRAL and Database of Systematic Reviews) and ClinicalTrials.gov) were searched in February 2019, using: 1) asthma-related key words: asthma; AND 2) macrolide-related key words: macrolide* OR clarithromycin OR troleandomycin OR erythromycin OR josamycin OR azithromycin OR roxithromycin; AND 3) systematic review or RCT-related key words: modified version of the Cochrane sensitivity- and precision-maximising search [10] including randomised OR placebo OR clinical trial. The complete search strategy for each database is available in the supplementary material. Reference lists of previous systematic reviews were hand-searched for additional titles. 


\section{Study selection}

Study titles, abstracts and full-text articles were uploaded into Covidence (www.covidence.org). Two authors (S.A. Hiles and M. Guilhermino) independently screened the titles and abstracts. The full-text article of potentially eligible studies identified by either reviewer was reviewed in duplicate (S.A. Hiles and M. Guilhermino), with discrepancies resolved through consensus. Reasons for exclusion were recorded.

\section{Data extraction}

Study and sample characteristics (inclusion and exclusion criteria, design, age, sex, clinical characteristics, and central tendency and dispersion measures for primary and secondary outcomes) were extracted in duplicate (S.A. Hiles and M. Guilhermino) from eligible articles into a customised form in Covidence. Primary and secondary outcome data, blood or sputum eosinophil levels and severe asthma status were requested from RCT authors. The primary outcome was exacerbations during follow-up, which included temporary use or increase in OCS, use of antibiotics for lower respiratory tract infection, hospitalisation and/or emergency department visit for a deterioration in asthma, summarised via count, proportion of participants or time to first. Secondary outcomes included: 1) Asthma Control Questionnaire; 2) Asthma Quality of Life Questionnaire; 3) lung function (forced expiratory volume in $1 \mathrm{~s}$ $\left(\mathrm{FEV}_{1}\right)$ and forced vital capacity $(\mathrm{FVC})$ ); 4 ) number and type of side-effects (antibiotic-treated respiratory tract infections, nausea, diarrhoea, abdominal pain, other gastrointestinal tract problems, headache, vertigo, tinnitus, hearing loss, abnormal liver function tests, oral thrush, allergy, rash, corrected QT (QTc) prolongation and other adverse events); 5) number of study withdrawals; 6) eosinophil and neutrophil count in peripheral blood samples and/or in sputum samples; and 7) number of patients with pathogenic microorganisms present, including number of macrolide-resistant pathogens.

\section{Risk of bias assessment}

Risk of bias was assessed by two authors not involved in the published RCTs (S.A. Hiles and M. Guilhermino) using the Cochrane Risk of Bias Tool [10] that assesses the sequence generation, allocation concealment, blinding of participants, personnel and outcome assessors, incomplete outcome data, selective outcome reporting, and other sources of bias. Discrepancies were resolved by consensus.

\section{Data analysis}

IPD meta-analysis was conducted in Stata/IC version 15 (StataCorp, College Station, TX, USA) and conventional random effects meta-analysis in R (www.r-project.org) using the "meta" package [11]. To ensure accuracy, we replicated the RCT publication results in the data received from study authors. No queries arose. We conducted primary outcome IPD meta-analyses using a one-step method [12]. This involved compiling a dataset of participants from each study, then entering study as a random intercept in multilevel mixed model analysis with linear, logistic and negative binomial regression used as appropriate. We conducted the analysis in the whole cohort of participants with asthma, and in subgroups defined as: 1) noneosinophilic asthma ( $<3 \%$ sputum eosinophils or, if unavailable, $<300$ blood eosinophils $\left.\mu \mathrm{L}^{-1}\right)$, 2) eosinophilic asthma ( $\geqslant 3 \%$ sputum eosinophils or, if unavailable, $\geqslant 300$ blood eosinophils $\mu \mathrm{L}^{-1}$ ) and 3) severe asthma (asthma that requires treatment with high-dose ICS ( $\geqslant 1000 \mu \mathrm{g}$ fluticasone or equivalent) plus a second controller and/or systemic corticosteroids to prevent symptoms from becoming uncontrolled or that remains uncontrolled despite this treatment [13]).

Pre-specified sensitivity analyses were conducted using blood eosinophil thresholds $\geqslant 150, \geqslant 200$ and $\geqslant 300$ counts $\mu \mathrm{L}^{-1}$. For each study where data were available, we generated a standardised primary end-point for exacerbation: asthma deterioration requiring at least 3 days of systemic corticosteroids, respiratory tract infection requiring antibiotics, hospitalisation and/or emergency department visit. We also conducted analyses separately for exacerbation subtypes of OCS use, antibiotic use, emergency department visit and hospitalisation. Random effects meta-analysis was conducted for the secondary outcomes (change scores for continuous outcomes or number of participants with event for binary outcomes), calculating aggregated standardised mean differences (Hedge's $g$ ) or odds ratios, as appropriate. Since few studies were identified, planned meta-regression and subgroup analyses to explore sources of heterogeneity were not conducted. Heterogeneity was not quantified using $I^{2}$ as it is biased in small meta-analyses [14].

\section{Results}

\section{Study characteristics}

The systematic search identified 1864 studies, 501 of which were duplicates, leaving 1363 that were screened. Table 1 describes the three studies that met inclusion criteria after full-text review [5, 7, 15]. Reasons for exclusion are presented in figure 1. Risk of bias was generally low across studies (table 2). Two studies, AZISAST [7] and AMAZES [5], contributed data to the IPD meta-analyses of the primary exacerbation end-point and exacerbations according to asthma subtypes. In AZISAST [7], 70 patients (65\%) 


\begin{tabular}{|c|c|c|c|}
\hline & GiBson et al. [5] & BrusselLe et al. [7] & HAHN et al. [15] \\
\hline Design & Parallel-group, double-blind, placebo-controlled RCT & Parallel-group, double-blind, placebo-controlled RCT & Parallel-group, double-blind placebo-controlled RCT \\
\hline $\begin{array}{l}\text { Randomised to } \\
\text { macrolide/ } \\
\text { placebo } \mathrm{n}\end{array}$ & $213 / 207$ & $55 / 54$ & $38 / 37$ \\
\hline $\begin{array}{l}\text { Macrolide type and } \\
\text { regimen }\end{array}$ & Azithromycin, $500 \mathrm{mg}, 3$ times week & $\begin{array}{l}\text { Azithromycin, } 250 \mathrm{mg} \text { capsule, once daily for } 5 \text { days and then } \\
\text { one capsule } 3 \text { times a week }\end{array}$ & $\begin{array}{l}\text { Azithromycin, } 600 \mathrm{mg} \text { tablet, once daily for } 3 \text { days then one } \\
\text { tablet weekly for } 11 \text { weeks }\end{array}$ \\
\hline $\begin{array}{l}\text { Duration of } \\
\text { treatment }\end{array}$ & 48 weeks & 26 weeks; with a study drug-free washout period of 4 weeks & 12 weeks; follow-up until 1 year after randomisation \\
\hline Setting, country & Multicentre hospital-based, Australia & Multicentre hospital-based, Belgium & Primary care, practice-based, USA \\
\hline Asthma criteria & $\begin{array}{c}\text { Asthma (evidence of variable airflow limitation: post-bronchodilator } \\
\text { reversibility } \geqslant 12 \% \text { and at least } 200 \mathrm{~mL} \mathrm{FEV}_{1} \text {, airway } \\
\text { hyperresponsiveness or increased peak flow variability }>12 \% \text { of } \\
\text { amplitude above the lowest peak expiratory flow over at least } \\
1 \text { week of monitoring); currently symptomatic with at least partial } \\
\text { loss of asthma control (ACQ6 } \geqslant 0.75 \text { ) despite treatment with } \\
\text { maintenance ICS and LABA }\end{array}$ & $\begin{array}{l}\text { Severe asthma (GINA step } 4 \text { or } 5 \text { clinical features, received high } \\
\text { doses of ICS ( } 1000 \mu \mathrm{g} \text { fluticasone) plus inhaled LABA for at } \\
\text { least } 6 \text { months prior to screening; at least two independent } \\
\text { severe asthma exacerbations requiring systemic corticosteroids } \\
\text { and/or LRTI requiring antibiotics within the previous } 12 \text { months) }\end{array}$ & $\begin{array}{l}\text { Asthma (evidence of variable airflow limitation: a } 12 \% \text { and } \\
200 \mathrm{~mL} \text { change in } \mathrm{FEV} \text { and/or a } 25 \% \text { and } 60 \mathrm{~L} \cdot \mathrm{min}^{-1} \text { change in } \\
\text { peak expiratory flow rate; symptomatic } \geqslant 2 \text { days.week } \\
\geqslant 2 \text { nights } \text { month }^{-1} \text { or in exacerbation) }\end{array}$ \\
\hline $\begin{array}{l}\text { Primary efficacy } \\
\text { outcome }\end{array}$ & $\begin{array}{l}\text { Total number of asthma exacerbations (severe and moderate) and } \\
\text { asthma quality of life. Severe exacerbations were defined as } \\
\text { worsening of asthma symptoms that led to one of the following: } \\
\text { 1) at least } 3 \text { days of systemic corticosteroid treatment of at least } \\
10 \mathrm{mg}^{-1 d a y^{-1}} \text { or a temporary increase in a stable OCS maintenance } \\
\text { dosage of at least } 10 \mathrm{mg} \text {-day }{ }^{-1} \text { for at least } 3 \text { days; } 2 \text { ) an } \\
\text { asthma-specific hospitalisation or } 3 \text { ) an emergency department } \\
\text { visit requiring systemic corticosteroids. Moderate exacerbations } \\
\text { were defined as any temporary increase in ICS or antibiotics in } \\
\text { conjunction with a deterioration in asthma symptoms or both } \\
\text { (change in ACQ6 of } \geqslant 0.5 \text { or increased diary symptom score), or any } \\
\text { increase in } \beta_{2} \text {-agonist use for at least } 2 \text { days, or an emergency } \\
\text { department visit not requiring systemic corticosteroids. }\end{array}$ & $\begin{array}{l}\text { Rate of primary end-points (severe asthma exacerbations and/ } \\
\text { or LRTI requiring antibiotics). Severe asthma exacerbations } \\
\text { were defined as deterioration in asthma leading to at least one } \\
\text { of the following: 1) hospitalisation; 2) emergency department } \\
\text { visit and/or 3) need for systemic corticosteroids for at least } \\
3 \text { days. }\end{array}$ & $\begin{array}{l}\text { Overall asthma symptoms, measured on a } 5 \text {-point scale. } \\
\text { Exacerbation secondary outcome, which was used in the } \\
\text { current meta-analysis: steroid bursts, unscheduled or } \\
\text { emergency visit and/or a hospitalisation for asthma. }\end{array}$ \\
\hline \multicolumn{4}{|l|}{$\begin{array}{l}\text { Patient } \\
\text { characteristics } \\
\text { Age years }\end{array}$} \\
\hline Azithromycin & $61(51-69)$ & $53(46-64)$ & $45.7(15.5)$ \\
\hline Placebo & $60(50-68)$ & $53(36-60)$ & $47.4(14.2)$ \\
\hline \multicolumn{4}{|l|}{ Female } \\
\hline Azithromycin & $134(63)$ & $29(53)$ & $27(71)$ \\
\hline Placebo & $121(58)$ & $38(70)$ & $24(65)$ \\
\hline \multicolumn{4}{|l|}{ Lung function" } \\
\hline \multicolumn{4}{|l|}{$\mathrm{FEV}_{1}{ }^{\pi}$} \\
\hline Azithromycin & $72.3 \pm 20.7$ & $80.1 \pm 21.9$ & $2.33 \pm 1.05$ \\
\hline Placebo & $73.6 \pm 18.8$ & $84.8 \pm 20.7$ & $2.24 \pm 1.25$ \\
\hline \multicolumn{4}{|l|}{$\mathrm{FEV}_{1} / \mathrm{FVC}^{2} \%$} \\
\hline Azithromycin & $67.5 \pm 12.9$ & $66.8 \pm 12.3$ & \\
\hline Placebo & $68.3 \pm 11.9$ & $67.8 \pm 12.1$ & \\
\hline
\end{tabular}

Data for patient characteristics are presented as median (interquartile range), $\mathrm{n}(\%)$ or mean $\pm \mathrm{SD}$. RCT: randomised controlled trial; $\mathrm{FEV}{ }_{1}$ : forced expiratory volume in $1 \mathrm{~s} ; \mathrm{ACQ}$ : Asthma Control Questionnaire; ICS: inhaled corticosteroid; LABA: long-acting $\beta_{2}$-agonist; GINA: Global Initiative for Asthma; LRTI: lower respiratory tract infection; OCS: oral corticosteroid; FVC:

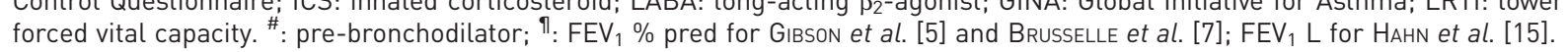




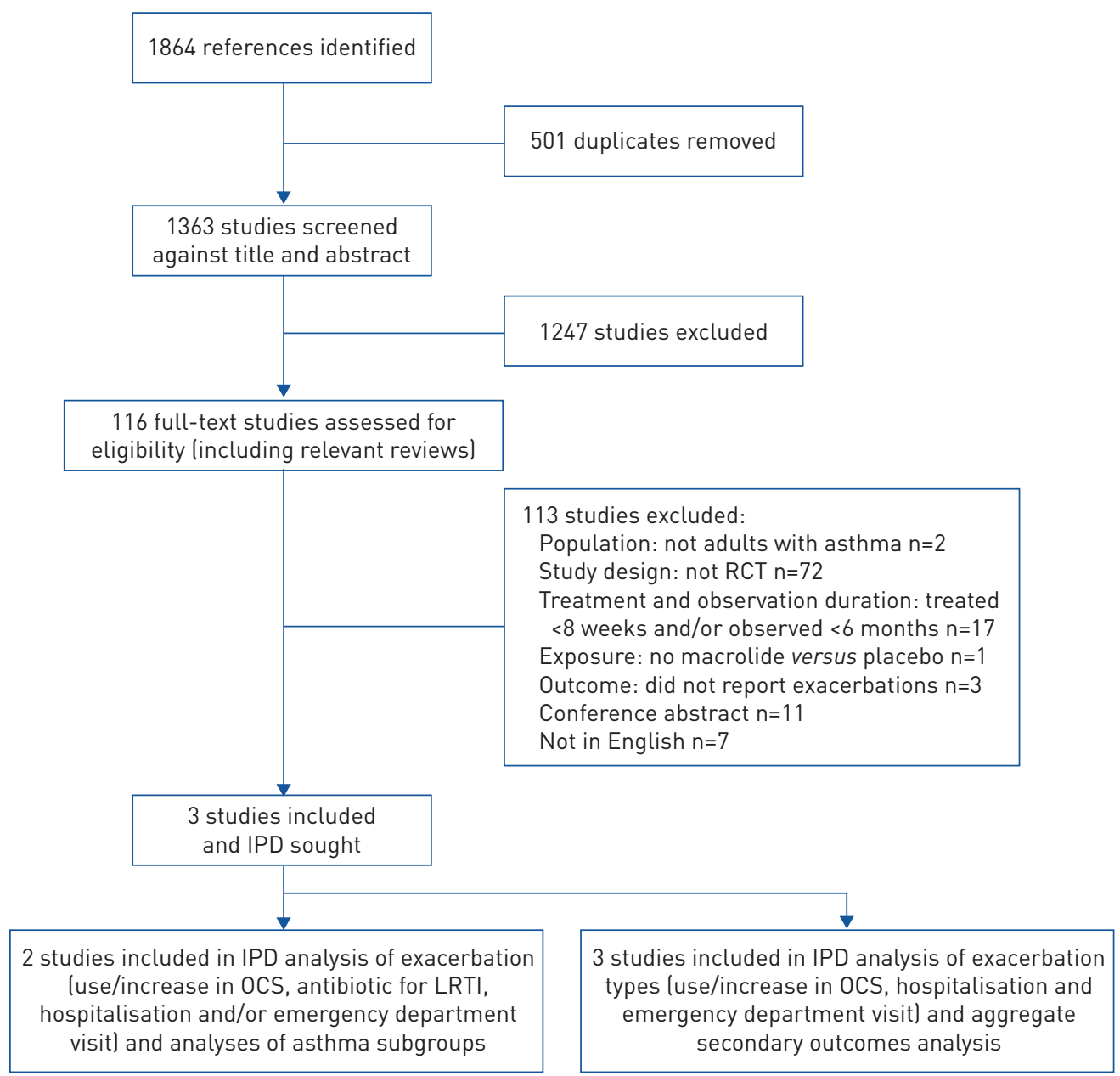

FIGURE 1 Article exclusion flowchart. RCT: randomised controlled trial; IPD: individual participant data; OCS: oral corticosteroid; LRTI: lower respiratory tract infection.

were classified as noneosinophilic and 38 (35\%) as eosinophilic; all were using ICS. In AMAZES [5], 224 (53\%) were noneosinophilic (99.6\% using ICS) and 196 (47\%) were eosinophilic (100\% using ICS). All patients in AZISAST and 211 (50.2\%) in AMAZES had severe asthma. An additional study, AZMATICS [15], did not measure blood or sputum eosinophils, or exacerbations for which antibiotics were prescribed, and so only contributed to the IPD meta-analysis regarding proportion of participants who used a course of OCS, were hospitalised or visited the emergency department for asthma.

\section{Asthma exacerbations}

Azithromycin reduced the rate of asthma exacerbations (OCS or antibiotic use, hospitalisation and/or emergency department visits) during follow-up (incidence rate ratio (IRR) 0.61 , 95\% CI 0.49-0.78; $\mathrm{p}<0.001 ; \mathrm{n}=529$, two studies) (figure 2). The reduced rate was similar in noneosinophilic asthma (IRR $0.61,95 \%$ CI $0.45-0.82 ; \mathrm{p}=0.001 ; \mathrm{n}=294$, two studies), eosinophilic asthma (IRR 0.63, 95\% CI 0.44-0.92; $\mathrm{p}=0.015 ; \mathrm{n}=234$, two studies) and severe asthma (IRR 0.69, 95\% CI 0.52-0.92; $\mathrm{p}=0.013 ; \mathrm{n}=320$, two studies). Sensitivity analysis using different blood eosinophil thresholds to define eosinophilic and noneosinophilic subgroups indicated very little difference in effect size (supplementary table S1).

Patients treated with azithromycin had lower odds of ever exacerbating during follow-up in the entire cohort (OR 0.58, 95\% CI 0.41-0.82; p=0.002) (figure 3a) and in eosinophilic asthma (OR 0.48, 95\% CI $0.28-0.81 ; \mathrm{p}=0.006$ ) (figure $3 \mathrm{c}$ ). Patients with noneosinophilic or severe asthma were also less likely to exacerbate in the azithromycin than placebo group; however, the difference between groups was not statistically significant (OR 0.68, 95\% CI 0.43-1.08; $\mathrm{p}=0.105$ and OR 0.68, 95\% CI 0.44-1.06; $\mathrm{p}=0.087$, respectively) (figure $3 \mathrm{~b}$ and $\mathrm{d}$ ). The hazard ratio (HR) for time to first exacerbation during follow-up was also statistically significant in the entire cohort (HR 0.71, 95\% CI 0.56-0.91; p=0.007) and in eosinophilic asthma (HR 0.67, 95\% CI 0.45-0.98; $\mathrm{p}=0.038$ ) (figure $4 \mathrm{a}$ and $\mathrm{c}$ ). The effect in noneosinophilic and severe 
TABLE 2 Risk of bias assessment

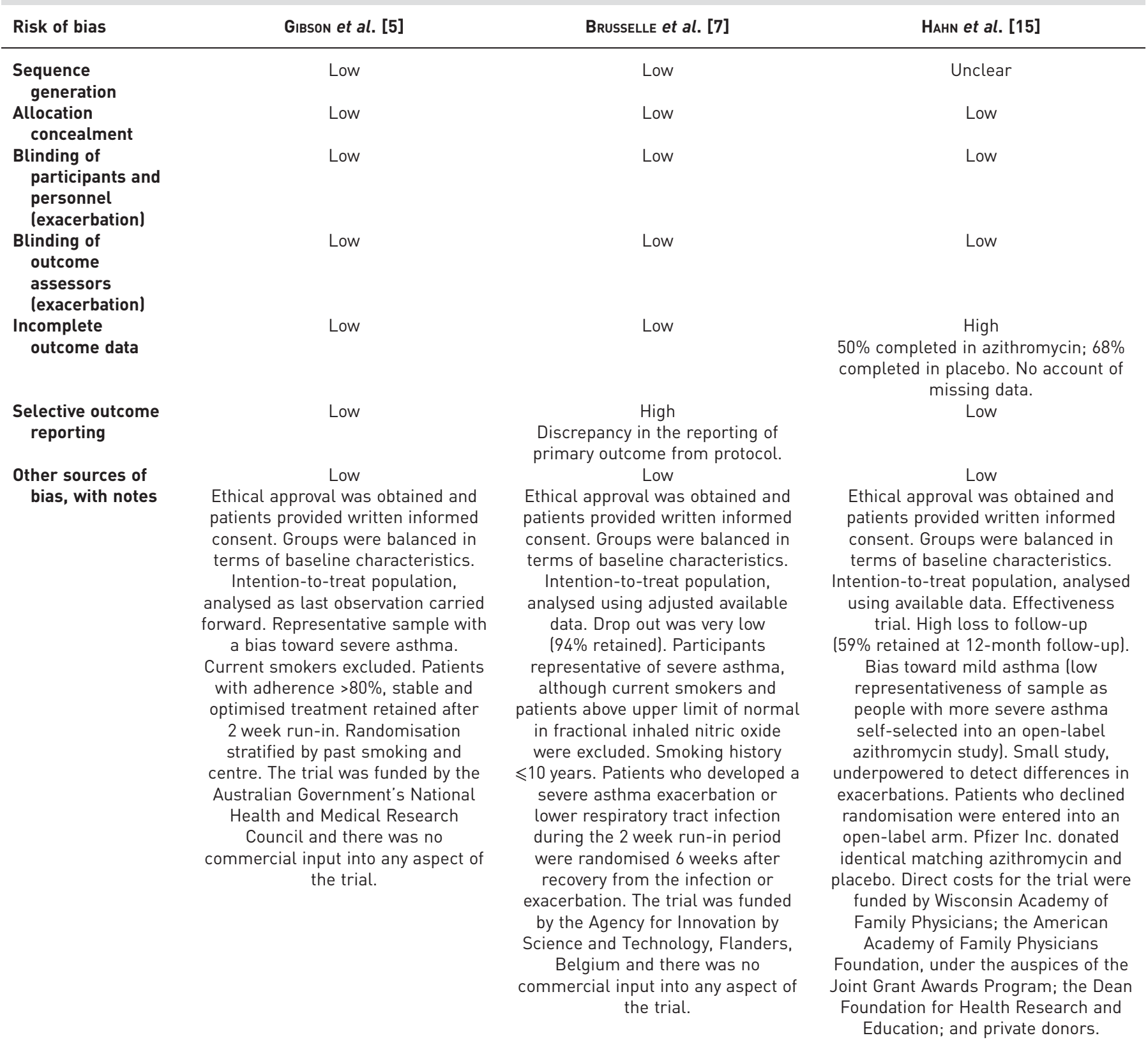

asthma was similar in magnitude, although not statistically significant (HR 0.75, 95\% CI 0.54-1.04; $\mathrm{p}=0.087$ and HR 0.80, 95\% CI 0.59-1.09; $\mathrm{p}=0.163$, respectively) (figure $4 \mathrm{~b}$ and $\mathrm{d}$ ).

\section{oCS courses}

The rate of OCS courses during follow-up did not differ between azithromycin and placebo groups in the entire cohort (IRR 0.74, 95\% CI 0.51-1.09; $\mathrm{p}=0.132$; two studies) nor in the subphenotypes noneosinophilic asthma (IRR $1.35,95 \%$ CI $0.80-2.28 ; \mathrm{p}=0.254$; two studies) and severe asthma (IRR 0.76, 95\% CI $0.48-1.20 ; \mathrm{p}=0.236$; two studies). In the azithromycin group, $26 \%$ of participants reported a course of OCS during follow-up compared with $28 \%$ in the placebo group (OR 0.92, 95\% CI 0.64-1.33; $\mathrm{p}=0.661$; $\mathrm{n}=597$, three studies) (figure 3a). Participants with noneosinophilic and severe asthma were also no more likely to report an OCS course in the azithromycin than placebo group (OR 1.34, 95\% CI 0.76-2.34; $\mathrm{p}=0.312$; two studies and OR $0.82,95 \%$ CI $0.50-1.35 ; \mathrm{p}=0.441$; two studies, respectively) (figure $3 \mathrm{~b}$ and $\mathrm{d}$ ). However, in eosinophilic asthma, azithromycin led to a significantly reduced rate of OCS courses (IRR 
0.42, 95\% CI 0.23-0.78; $\mathrm{p}=0.006$; two studies) and decreased likelihood of reporting an OCS course (OR 0.48, 95\% CI 0.26-0.89; $\mathrm{p}=0.019$; two studies) (figure $3 \mathrm{c}$ ).

\section{Antibiotic use for respiratory infections}

Azithromycin reduced the rate of antibiotic use for respiratory infections in the entire cohort (IRR 0.54, 95\% CI 0.38-0.76; $\mathrm{p}=0.001$; two studies), noneosinophilic asthma (IRR 0.36, 95\% CI 0.22-0.56; $\mathrm{p}<0.001$;

FIGURE 2 Incidence rate ratio (IRR) and $95 \%$ confidence interval for exacerbations comparing azithromycin and placebo. IRR <1 indicates a larger reduction in the number of exacerbations for the azithromycin group.
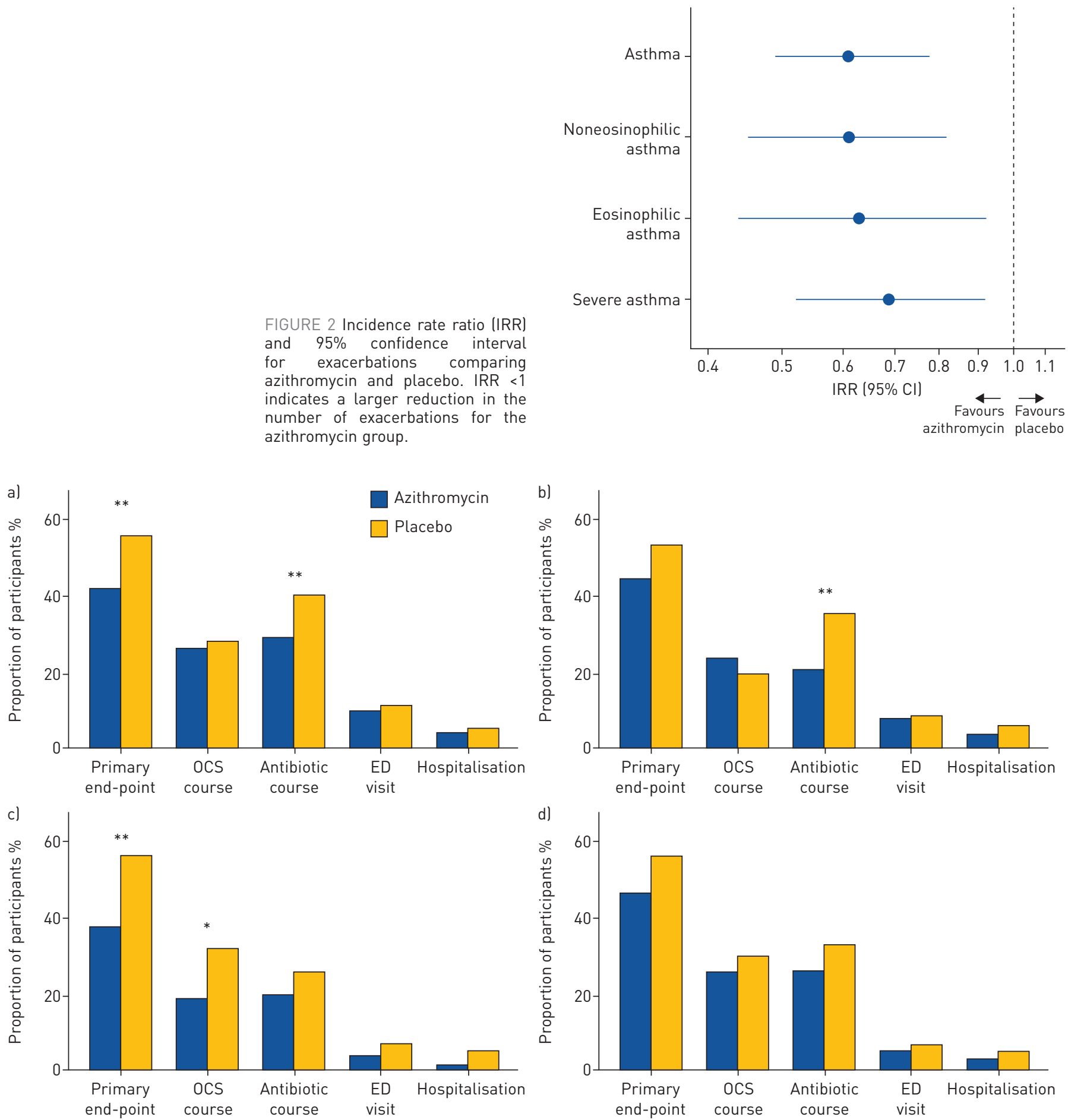

FIGURE 3 Proportion of participants who reported an oral corticosteroid (OCS) or antibiotic course, emergency department (ED) visit and/or hospitalisation (combined as primary end-point and individually) over follow-up in a) asthma overall (n=529 for primary end-point and antibiotic course; remaining $n=597)$, b) noneosinophilic asthma $(n=294), c)$ eosinophilic asthma $(n=234)$ and d) severe asthma ( $n=320)$. One participant in AZISAST [7] had no data on phenotype. ${ }^{*}: p<0.05 ;{ }^{* *}: p<0.01$. 

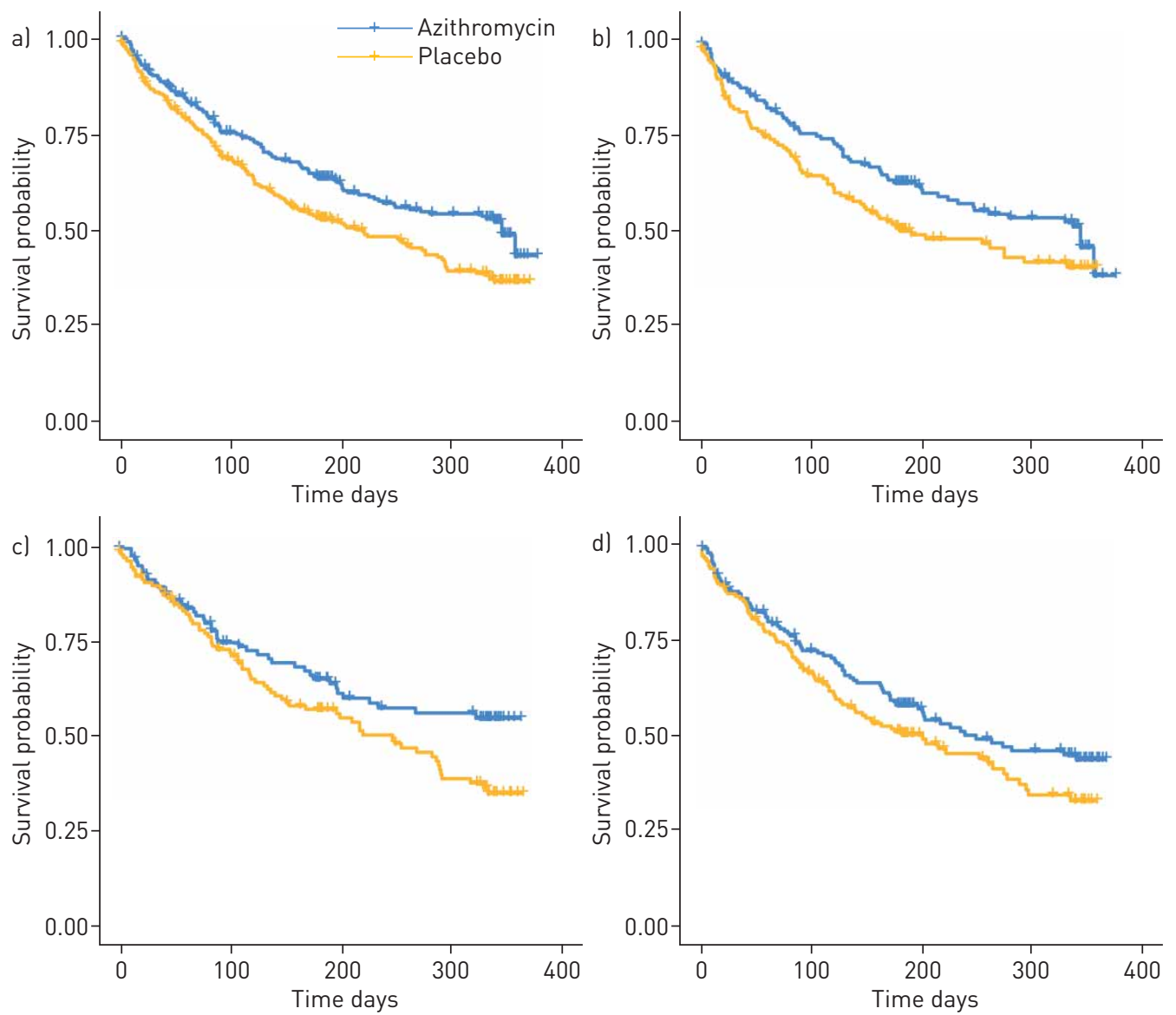

FIGURE 4 Exacerbation-free survival curves for time to first exacerbation loral corticosteroid course, antibiotic course, emergency department visit and/or hospitalisation for asthmal in al asthma overall, b) noneosinophilic asthma, c) eosinophilic asthma and d) severe asthma.

two studies) and severe asthma (IRR $0.65,95 \%$ CI $0.43-0.97$; $\mathrm{p}=0.037$; two studies). Significantly fewer patients in the azithromycin group compared with the placebo group reported use of antibiotics during follow-up in the cohort overall (OR $0.55,95 \%$ CI $0.37-0.82$; $\mathrm{p}=0.003$; two studies) and noneosinophilic asthma specifically (OR $0.47,95 \%$ CI $0.28-0.79 ; \mathrm{p}=0.005$; two studies) (figure $3 \mathrm{a}$ and $\mathrm{b}$ ). In severe asthma, the azithromycin group was also less likely to report any antibiotic use during follow-up, although the difference was smaller in magnitude and nonsignificant (OR 0.70, 95\% CI 0.43-1.13; $\mathrm{p}=0.146$; two studies) (figure 3d). In eosinophilic asthma, azithromycin did not reduce the rate (IRR 1.00, 95\% CI 0.58-1.72; $p=0.994$; two studies) or occurrence of antibiotic use (OR $0.69,95 \%$ CI $0.37-1.27 ; p=0.234$; two studies) (figure 3c).

\section{Hospitalisation}

Hospitalisation was infrequent, with similar prevalence reported in both the azithromycin (4\%) and placebo groups (5\%; OR 0.71, 95\% CI 0.32-1.56; $\mathrm{p}=0.390 ; \mathrm{n}=597$, three studies) (figure 3a). Similar effects were observed in the asthma subgroups (noneosinophilic asthma OR 0.76, 95\% CI 0.27-2.16; $\mathrm{p}=0.611$; eosinophilic asthma OR $0.17,95 \%$ CI $0.02-1.47$; $\mathrm{p}=0.108$; severe asthma OR $0.49,95 \%$ CI $0.14-1.71$; $\mathrm{p}=0.266$; two studies) (figure $3 \mathrm{~b}-\mathrm{d}$ ).

\section{Emergency department visit}

Emergency department visits were equally common in the azithromycin (10\%) and placebo groups (11\%) (OR $0.87,95 \%$ CI $0.50-1.51 ; \mathrm{p}=0.620 ; \mathrm{n}=597$, three studies) (figure $3 \mathrm{a}$ ). There were similarly no differences in frequency of emergency department visits in the subgroups (noneosinophilic OR $0.87,95 \%$ CI 0.38-2.02; $\mathrm{p}=0.754$; eosinophilic OR $0.47,95 \%$ CI 0.14-1.55; $\mathrm{p}=0.214$; severe asthma OR $0.69,95 \%$ CI $0.27-1.80$; $\mathrm{p}=0.450$; two studies) (figure $3 \mathrm{~b}-\mathrm{d}$ ). 


\section{Secondary outcomes}

Improvements in asthma-related quality of life were greater in the azithromycin group; however, the pooled effect size was not statistically significant (standardised mean difference $0.161,95 \%$ CI $-0.005-0.327$; $\mathrm{p}=0.058$ ) (figure 5). Changes in asthma control score, pre-bronchodilator $\mathrm{FEV}_{1} \%$ pred and FVC \% pred, and peripheral blood and sputum eosinophil and neutrophil counts were equivocal between azithromycin and placebo groups (figure 5). Side-effects were similar between azithromycin and placebo groups (figure 6).

\section{Discussion}

This IPD meta-analysis demonstrated that maintenance treatment with azithromycin reduces exacerbations over a period of up to 12 months, and provides evidence of this benefit in patients with eosinophilic and noneosinophilic asthma. The IPD meta-analysis also provides the first level 1 data demonstrating that azithromycin effectively reduces exacerbations in severe asthma. Another novel finding

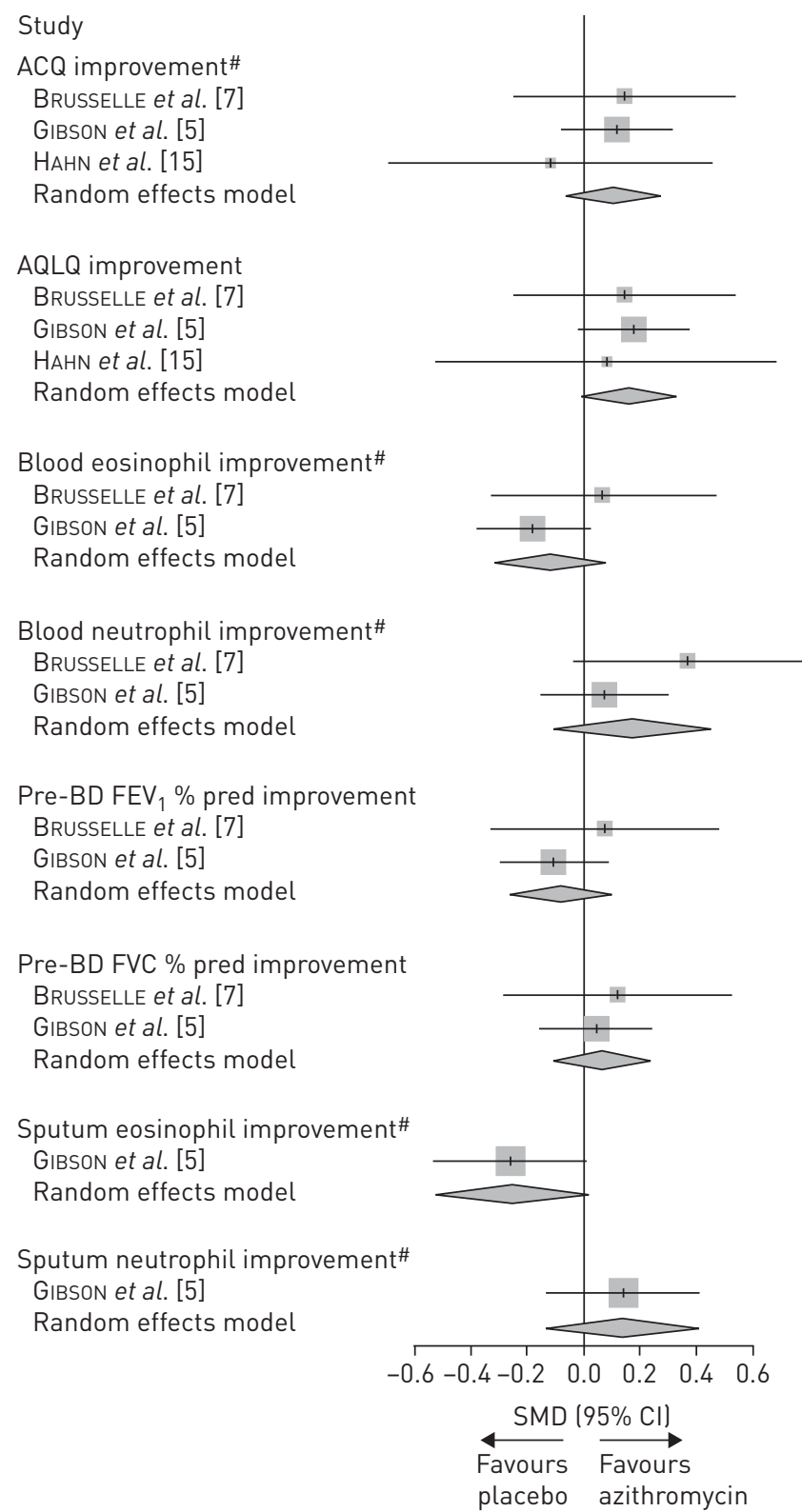

FIGURE 5 Random effects meta-analyses comparing azithromycin and placebo groups for secondary outcomes. SMD: standardised mean difference; ACQ: Asthma Control Questionnaire; AQLQ: Asthma Quality of Life Questionnaire; BD: bronchodilator; $\mathrm{FEV}_{1}$ : forced expiratory volume in $1 \mathrm{~s}$; FVC: forced vital capacity. ${ }^{\#}$ : note that for illustration each metric has been coded in the same direction to indicate an "improvement" (i.e. AQLQ where an increase in score represents an improvement and lung function where an increase in volume represents an improvement; with remainder a decrease in magnitude of the metric represents an improvement). SMD >0 indicates a greater improvement (either decrease or increase, as appropriate) in the azithromycin group. 
Study

Abdominal pain

BRUSSELLe et al. [7]

GIBSON et al. [5]

Random effects model

Abnormal liver function tests

BRUSSELLe et al. [7]

GIBSON et al. [5]

Random effects model

Allergy/allergic reaction BRUSSELLe et al. [7]

GIBSON et al. [5]

Random effects model

Diarrhoea

BRUSSELLe et al. [7]

GIBSON et al. [5]

HAHN et al. [15]

Random effects model

Discontinuation due to $\mathrm{AE}$ BRUSSELLe et al. [7]

GIBSON et al. [5]

Random effects model

Drug-related AEs

BRUSSELLE et al. [7]

Random effects model

Headache

BRUSSELLe et al. [7]

GIBSON et al. [5]

Random effects model

Hearing loss

GIBSON et al. [5]

HAHN et al. [15]

Random effects model

Leukopenia

BRUSSELle et al. [7]

Random effects model

Nausea

BRUSSELLe et al. [7]

GIBSON et al. [5]

HAHN et al. [15]

Random effects model

Oral thrush

GiBSon et al. [5]

Random effects model

Other gastrointestinal

GIBSON et al. [5]

Random effects model
Study

Pathogens: azithromycin resistant

GIBSON et al. [5]

Random effects model

Pathogens: PPOs

GiBson et al. [5]

Random effects model

QTc prolongation

GIBSON et al. [5]

Random effects model

Rash

GIBSON et al. [5]

HAHN et al. [15]

Random effects model

Serious AEs

BRUSSELLE et al. [7]

GIBSON et al. [5]

Random effects model

Stomach pain

HAHN et al. [15]

Random effects model

Swelling

HAHN et al. [15]

Random effects model

Thrombocytopenia

BRUSSELLE et al. [7]

Random effects model

Tinnitus

GIBSon et al. [5]

Random effects model

Vaginal candidiasis

HAHN et al. [15]

Random effects model

Vertigo

BRUSSELle et al. [7]

GIBSON et al. [5]

Random effects model

Vomiting

HAHN et al. [15]

Random effects model

Withdrawn

BRUSSELLe et al. [7]

GIBSON et al. [5]

HAHN et al. [15]

Random effects model

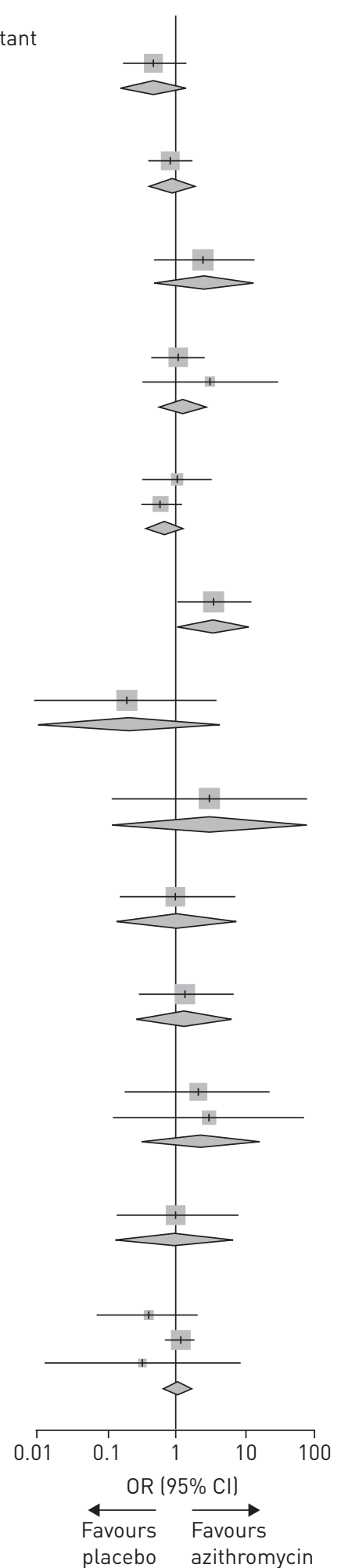

FIGURE 6 Random effects meta-analyses comparing azithromycin and placebo groups for secondary outcomes. AE: adverse event; PPO: potentially pathogenic organism; QTc: corrected QT. Odds ratio >1 indicates the side-effect was more common in the azithromycin group.

is that azithromycin reduced OCS courses in patients with eosinophilic asthma, and reduced antibiotic courses in noneosinophilic asthma. Azithromycin was also well tolerated, but had little effect on asthma control, quality of life, lung function and circulating eosinophils. Maintenance azithromycin use may be a strategy for reducing exacerbations in at-risk patients. 
Patients on ICS and LABA maintenance therapy remain at risk of asthma exacerbations. Long-term treatment with azithromycin prevents exacerbations in asthma and may be particularly useful in severe asthma patients, half of whom experience frequent exacerbations of two or more attacks per year [16]. Positive effects of macrolides may extend across airways disease; meta-analytic evidence in COPD [17] and bronchiectasis [18] indicates that $\geqslant 12$ weeks of prophylactic antibiotics (majority macrolides) reduced exacerbations and improved quality of life.

There is great promise for azithromycin, owing to its oral route of administration and relatively low cost. In the studies included in this review, azithromycin was well tolerated, although other larger meta-analyses in patients taking macrolides for any indication show gastrointestinal adverse events are more likely with macrolide use compared with placebo [19]. Questions that remain are whether other macrolides besides azithromycin produce similar effects and the optimal duration of treatment or dosing regimen for preventing exacerbation. In contrast to the current IPD meta-analysis, a previous larger meta-analysis with less stringent inclusion criteria that included various macrolides and shorter treatment/observation periods ( $78 \%$ of studies $<12$ weeks) concluded that macrolides performed no better than placebo at improving clinical outcomes, including preventing hospitalisation or OCS courses [4]. Similarly, limited evidence has been found supporting antibiotics as an acute treatment for asthma exacerbation (excluding prophylactic use) [20]. Further efficacy and effectiveness trials can address these unanswered questions.

Azithromycin was effective at reducing the overall rate of exacerbations in both eosinophilic and noneosinophilic asthma. However, different definitions of exacerbation led to inconsistent effects for phenotype, with reduced OCS courses in eosinophilic asthma and reduced antibiotic courses in noneosinophilic asthma. This observation highlights the need to evaluate closely the definition of exacerbation in research design. Furthermore, the exacerbation-free survival curves differ somewhat between eosinophilic asthma (late/progressive separation between azithromycin and placebo curves) and noneosinophilic asthma (early separation). The reason for the discrepancy for each phenotype is unclear. It may be that each phenotype has a different base rate of each exacerbation type. It may also suggest that azithromycin acts through multiple routes to reduce exacerbation. Macrolide antibiotics have antimicrobial and anti-inflammatory effects, particularly in modulating neutrophil and macrophage function, although the anti-inflammatory effects of azithromycin in particular may be less than other macrolides [3]. Antiviral effects of azithromycin in particular have been reported [21]. Anti-inflammatory effects may specifically benefit patients with type 2 inflammation, whereas antibiotic and antiviral effects may prevent respiratory infection in susceptible patients, particularly patients with neutrophilic inflammation. Further investigation of the mechanism of action may progress the move toward optimised targeted exacerbation prevention and management.

The main limitation of this IPD meta-analysis was the few studies that met eligibility, which prevented subgroup analysis to explore heterogeneity. Due to limitations in the available datasets, there were minor differences in the standardised primary outcome, which may have increased heterogeneity. Most participants in the IPD meta-analysis were recruited from hospital settings and many had severe asthma, so the results may not generalise to patients with mild-to-moderate asthma treated in primary care. In the noneosinophilic group, almost all were using ICS (99.7\%), most at high doses, and many used maintenance OCS. Therefore, this group likely includes patients with eosinophils suppressed by treatment; the extent to which this group are "noneosinophilic" without steroid treatment is unknown. Lastly, since macrolides have been shown to reduce exacerbations in patients with bronchiectasis [18], the benefit of azithromycin in patients with severe asthma might be influenced by patients with concomitant bronchiectasis, a well-known complication of long-standing asthma. However, we observed no evidence of effect modification by self-reported bronchiectasis diagnosis. In AZISAST, $<10 \%$ of the enrolled patients with severe asthma had evidence of bronchiectasis on high-resolution computed tomography scan at study entry.

Exacerbations are costly to the individual and the healthcare system through direct healthcare costs, and to the broader economy through lost productivity $[22,23]$. They are also associated with health status in patients [24]. Eliminating exacerbations is an important therapeutic goal, which long-term treatment with azithromycin may in part realise. Additionally, OCS use is costly, leading to increased economic burden [25], health status impairment [26] and comorbidity [27]. A cumulative dose as low as $1 \mathrm{~g}$ is associated with adverse consequences and comorbidities [27]. Furthermore, the use of OCS among patients with severe asthma is excessive, with $25 \%$ of Australian patients with severe disease using maintenance OCS [16]. Thus, reducing OCS use is a major goal of asthma management and azithromycin may contribute to the attainment of this goal in patients with eosinophilic inflammation. However, there are a number of important considerations when using azithromycin in asthma. To minimise antibiotic resistance, we suggest that the initiation of azithromycin is prescribed and monitored by a specialist respiratory physician. Given the skew toward severe patients in the current IPD meta-analysis, the role of 
azithromycin in nonsevere asthma is uncertain, with the most convincing evidence that azithromycin is suitable for severe asthma and those at high risk of exacerbation. Treatment period should be pre-determined, with a duration of at least 3 months up to 1 year. We suggest azithromycin is avoided in patients with a prolonged QTc interval $(>450 \mathrm{~ms})$ or cardiac arrhythmia and in those with significant hearing loss. Patients should be monitored for adverse effects, in particular gastrointestinal effects, rhabdomyolysis among statin users, hearing loss and antibiotic resistance [19, 28]. Finally, with the advent of monoclonal antibody therapies, the role of azithromycin for patients with severe eosinophilic asthma requires consideration. In low-income countries, maintenance azithromycin might be an alternative to biological therapies in severe eosinophilic asthma, due to high cost and unavailability. Elsewhere, given potential risks of individual- and community-level antibiotic resistance, ensuring patients are systematically assessed will help ensure the right patients receive the most appropriate treatments [29]. Maintenance azithromycin may be targeted to patients with severe noneosinophilic asthma. Anti-type 2 cytokine monoclonal antibodies may be preferred as add-on therapy in patients with uncontrolled severe eosinophilic asthma; however, maintenance azithromycin may address other factors such as residual exacerbation despite monoclonal antibody therapy, OCS burden and patient behavioural characteristics, including acceptance of and adherence to individual treatments.

This systematic review and IPD meta-analysis supports that long-term use of azithromycin, in conjunction with existing maintenance asthma treatment, reduces exacerbations in asthma as well as in severe, eosinophilic and noneosinophilic asthma subphenotypes. Since azithromycin is inexpensive, easily administered and effective at reducing exacerbations, it may be a worthwhile adjunct medication for well-selected patients at risk. Questions regarding optimal dose and duration, the effect of other macrolides besides azithromycin, and the effect of macrolides on community microbial resistance need to be addressed in future research.

Acknowledgements: We thank David Hahn (University of Wisconsin, Madison, WI, USA) and Heather Powell (University of Newcastle, Callaghan, Australia) who provided additional data for the meta-analysis. We thank Ling Qin (Central South University, Changsha, China) for reviewing articles in Chinese. We acknowledge Christine VanderStichele, Paul Jordens, René Deman, Hans Slabbynck, Veerle Ringoet, Geert Verleden, Ingel K. Demedts, Katia Verhamme, Anja Delporte, Bénédicte Demeyere, Geert Claeys, Jerina Boelens, Elizaveta Padalko, Johny Verschakelen, Georges Van Maele, Ellen Deschepper and Guy F.P. Joos for their contributions to AZISAST. We acknowledge Ian A. Yang, John W. Upham, Paul N. Reynolds, Sandra Hodge, Alan L. James, Christine Jenkins, Matthew J. Peters, Guy B. Marks, Melissa Baraket, Heather Powell, Steven L. Taylor, Lex E.X. Leong, Geraint B. Rogers and Jodie L. Simpson for their contributions to AMAZES. We acknowledge the AZMATICS Study Group for their contributions to AZMATICS.

Author contributions: All authors contributed to data interpretation and critical review of the manuscript. P.G. Gibson, V.M. McDonald, G.G. Brusselle and S.A. Hiles contributed to conceiving the study, developing the research question and/or developing the study design. S.A. Hiles conducted the systematic literature search, article reviews, risk of bias assessment, data analysis, generated figures and tables, and drafted the manuscript. M. Guilhermino completed article reviews and risk of bias assessment. P.G. Gibson and G.G. Brusselle provided primary data.

Conflict of interest: S.A. Hiles: salary was supported by a grant from GlaxoSmithKline paid to employer (University of Newcastle) during the conduct of the study; travel for collaboration was supported by a Hunter Medical Research Institute Jennie Thomas Medical Research Travel Grant; salary was supported by a grant from AstraZeneca paid to employer (University of Newcastle) outside the submitted work. V.M. McDonald reports grants from GlaxoSmithKline, during the conduct of the study; grants and personal fees for lectures from GlaxoSmithKline and AstraZeneca, personal fees for steering committee work from Menarini, outside the submitted work. M. Guilhermino has nothing to disclose. G.G. Brusselle reports personal fees for advisory board work and lectures from AstraZeneca, Boehringer Ingelheim, Chiesi, GlaxoSmithKline, Novartis and Teva, personal fees for advisory board work from Sanofi, outside the submitted work. P.G. Gibson reports grants and personal fees for educational activities from AstraZeneca, GlaxoSmithKline and Novartis, outside the submitted work.

\section{References}

McDonald VM, Gibson PG. Exacerbations of severe asthma. Clin Exp Allergy 2012; 42: 670-677.

Pavord ID, Beasley R, Agusti A, et al. After asthma: redefining airways diseases. Lancet 2018; 391: 350-400.

Zimmermann P, Ziesenitz VC, Curtis N, et al. The immunomodulatory effects of macrolides - a systematic review of the underlying mechanisms. Front Immunol 2018; 9: 302.

4 Kew KM, Undela K, Kotortsi I, et al. Macrolides for chronic asthma. Cochrane Database Syst Rev 2015; 9: CD002997.

5 Gibson PG, Yang IA, Upham JW, et al. Effect of azithromycin on asthma exacerbations and quality of life in adults with persistent uncontrolled asthma (AMAZES): a randomised, double-blind, placebo-controlled trial. Lancet 2017; 390: 659-668.

6 Global Initiative for Asthma. Difficult-to-Treat and Severe Asthma in Adolescent and Adult Patients: Diagnosis and Management. 2019. https://ginasthma.org/wp-content/uploads/2019/04/GINA-Severe-asthma-Pocket-Guidev2.0-wms-1.pdf Date last accessed: September 16, 2019.

7 Brusselle GG, VanderStichele C, Jordens P, et al. Azithromycin for prevention of exacerbations in severe asthma (AZISAST): a multicentre randomised double-blind placebo-controlled trial. Thorax 2013; 68: 322-329. 
8 Simpson JL, Powell H, Boyle MJ, et al. Clarithromycin targets neutrophilic airway inflammation in refractory asthma. Am J Respir Crit Care Med 2008; 177: 148-155.

9 Morrison A, Polisena J, Husereau D, et al. The effect of English-language restriction on systematic review-based meta-analyses: a systematic review of empirical studies. Int J Technol Assess Health Care 2012; 28: 138-144.

10 Higgins J, Green S, eds. Cochrane Handbook for Systematic Reviews of Interventions, Version 5.1.0 (updated March 2011). 2011. http://handbook-5-1.cochrane.org Date last accessed: September 16, 2019.

11 Schwarzer G. meta: an R package for meta-analysis. R News 2007; 7: 40-45.

12 Riley RD, Lambert PC, Staessen JA, et al. Meta-analysis of continuous outcomes combining individual patient data and aggregate data. Stat Med 2008; 27: 1870-1893.

13 Chung KF, Wenzel SE, Brozek JL, et al. International ERS/ATS guidelines on definition, evaluation and treatment of severe asthma. Eur Respir J 2014; 43: 343-373.

14 von Hippel PT. The heterogeneity statistic $I^{2}$ can be biased in small meta-analyses. BMC Med Res Methodol 2015; 15: 35-35.

15 Hahn DL, Grasmick M, Hetzel S, et al. Azithromycin for bronchial asthma in adults: an effectiveness trial. J Am Board Fam Med 2012; 25: 442-459.

16 McDonald VM, Hiles SA, Godbout K, et al. Treatable traits can be identified in a severe asthma registry and predict future exacerbations. Respirology 2019; 24: 37-47.

17 Wang Y, Zijp TR, Bahar MA, et al. Effects of prophylactic antibiotics on patients with stable COPD: a systematic review and meta-analysis of randomized controlled trials. J Antimicrob Chemother 2018; 73: 3231-3243.

18 Abu Dabrh AM, Hill AT, Dobler CC, et al. Prevention of exacerbations in patients with stable non-cystic fibrosis bronchiectasis: a systematic review and meta-analysis of pharmacological and non-pharmacological therapies. $B M$ J Evid Based Med 2018; 23: 96-103.

19 Hansen MP, Scott AM, McCullough A, et al. Adverse events in people taking macrolide antibiotics versus placebo for any indication. Cochrane Database Syst Rev 2019; 1: CD011825.

20 Normansell R, Sayer B, Waterson S, et al. Antibiotics for exacerbations of asthma. Cochrane Database Syst Rev 2018; 6: CD002741.

21 Gielen V, Johnston SL, Edwards MR. Azithromycin induces anti-viral responses in bronchial epithelial cells. Eur Respir J 2010; 36: 646-654.

22 Ivanova JI, Bergman R, Birnbaum HG, et al. Effect of asthma exacerbations on health care costs among asthmatic patients with moderate and severe persistent asthma. J Allergy Clin Immunol 2012; 129: 1229-1235.

23 Hiles SA, Harvey ES, McDonald VM, et al. Working while unwell: workplace impairment in people with severe asthma. Clin Exp Allergy 2018; 48: 650-662.

24 Luskin AT, Chipps BE, Rasouliyan L, et al. Impact of asthma exacerbations and asthma triggers on asthma-related quality of life in patients with severe or difficult-to-treat asthma. J Allergy Clin Immunol Pract 2014; 2: 544-552.

25 Barry LE, Sweeney J, O'Neill C, et al. The cost of systemic corticosteroid-induced morbidity in severe asthma: a health economic analysis. Respir Res 2017; 18: 129.

26 McDonald VM, Kennington E, Hyland ME. Understanding the experience of people living with severe asthma. In: Chung KF, Israel E, Gibson PG, eds. Severe Asthma (ERS Monograph). Sheffield, European Respiratory Society, 2019; pp. 16-29.

27 Price DB, Trudo F, Voorham J, et al. Adverse outcomes from initiation of systemic corticosteroids for asthma: long-term observational study. J Asthma Allergy 2018; 11: 193-204.

28 Strandell J, Bate A, Hagg S, et al. Rhabdomyolysis a result of azithromycin and statins: an unrecognized interaction. Br J Clin Pharmacol 2009; 68: 427-434.

29 Gibson PG, McDonald VM. Management of severe asthma: targeting the airways, comorbidities and risk factors. Intern Med J 2017; 47: 623-631. 